\title{
Modifikasi Campuran Hot Rolled Sheet - WC Dengan Campuran Serbuk Arang Tempurung Kelapa
}

\author{
Moch. Shodiq Zamroji ${ }^{1}$, Kurnia Hadi Putra ${ }^{2}$ \\ ${ }^{1,2}$ Jurusan Teknik Sipil, Fakultas Teknik Sipil dan Perencanaan, Institut Teknologi Adhi Tama Surabaya \\ Email: mochshodiqzzz@gmail.com
}

\begin{abstract}
Highway has vital roles in the growth of economic, social and culture, tourism development as it can support national development. On the one side, rapid development of society has triggered more uses of vehicles, on the other side, weather and temperature have brought great effects to the quality of asphalt surface layer, thereby causing many roads to be inappropriate to their planned ages. One of pavement types generally used in Indonesia is Hot Rolled Sheet (HRS) type. This study used Coconut Shell Charcoal containing activated carbon to make test specimen mixture. The aim of this research was to investigate the effects of Hot Rolled Sheet - WC mixture by adding coconut shell charcoal powder. Qualitative method was employed in this research for analyzing the result of marshal test. The researcher gave additional coconut shell charcoal powder in several levels, such as 0\%, 2\%, 4\%, 6\%, 8\%, and 10\%. Testing the coconut shell charcoal powder mixture got the optimum result by the content 4\% having the highest stability value 1191.10 kilograms, marshal quotient value $374.17 \mathrm{~kg} / \mathrm{mm}$, VIM value $4.34 \%$, and VMA value $18.65 \%$. Accordingly, the stability, VM, and VMA increased and were in accordance with the general specification of Bina Marga 2018, but the values of flow and VFB decreased along with the coconut shell charcoal powder addition respectively by 3.18 and VFB $76.70 \%$. Overall, the additional content 4\% has met the general specification of Bina Marga 2018.
\end{abstract}

Keywords: Coconut Perfect Charcoal Powder, General Specification of Bina Marga 2018, HRS $W C$

\begin{abstract}
Abstrak
Jalan raya memiliki peranan penting dalam pertumbuhan ekonomi, sosial dan budaya, pembangunan pariwisata, dan untuk menunjang pembangunan nasional. Dengan perkembangan masyarakat yang begitu pesat mengakibatkan tingkat penggunaan kendaraan semakin banyak, Sementara itu cuaca dan suhu juga mempengaruhi kualitas lapis permukaan aspal, dan itu menyebabkan banyak jalan yang tidak sesuai dengan umur yang telah direncanakan. Salah satu jenis perkerasan yang pada umumnya digunakan di Indonesia adalah jenis Hot Rolled Sheet (HRS), Peneliti kali ini menggunakan Arang Tempurung Kelapa (Coconut Shell Charcoal) yang mengandung karbon aktif yang digunakan sebagai campuran pembuatan benda uji. Tujuan daripada Penelitian ini adalah yaitu untuk mengetahui kualitas dari pengaruh campuran Hot Rolled Sheet - WC dengan penambahan bahan serbuk arang tempurung kelapa. Pada penelitian ini menggunakan metode kualitatif dalan menganalisa hasil uji dengan marshall test. Pada penelitian ini menggunakan penambahan serbuk arang tempurung kelapa dengan kadar $0 \%, 2 \%, 4 \%, 6 \%$, $8 \%$, dan $10 \%$. Hasil Pengujian dari pencampuran serbuk arang tempurung kelapa dengan hasil optimum yaitu pada kadar 4\%, dengan nilai stabilitas paling tinggi yaitu 1191,10 kg, sedangkan untuk nilai marshall quotient yaitu $374,17 \mathrm{~kg} / \mathrm{mm}$, untuk nilai VIM yaitu 4,34\% dan nilai VMA yaitu $18,65 \%$. Untuk stabilitas, VIM, dan Vma mengalami peningkatan dan sesuai dengan spedifikasi umum bina marga 2018, tapi untuk nilai flow dan VFB menurun dengan seiring penambahan kadar serbuk arang tempurung kelapa yaitu dengan nilai flow sebesar 3,18 dan VFB sebesar 76,70. Secara menyeluruh pada kadar penambahan $4 \%$ telah memenuhi persyaratan spesifikasi umum bina marga 2018.
\end{abstract}

Kata Kunci: HRS - WC, marshall test, Serbuk Arang Tempurng Kelapa, spesifikasi umum bina marga 2018 


\section{Pendahuluan}

Jalan Raya merupakan salah satu prasarana transportasi darat yang meliputi bagian bagian jalan, termasuk bangunan pelengkap dan kelengkapannya yang diperuntukan bagi lalu lintas. Dengan perkembangan masyarakat yang begitu pesat mengakibatkan tingkat penggunaan kendaraan semakin banyak, Sementara itu cuaca dan suhu juga mempengaruhi kualitas lapis permukaan aspal, dan itu menyebabkan banyak jalan yang tidak sesuai dengan umur yang telah direncanakan, semakin banyak kerusakan yang terjadi pada jalan maka semakin tinggi juga tingkat resiko pengguna jalan mengalami kecelakaan pada jalan tersebut.

Salah satu jenis perkerasan yang pada umumnya digunakan di Indonesia adalah jenis Hot Rolled Sheet (HRS), HRS sendiri memiliki dua lapis yaitu Hot Rolled Sheet Base (HRS - Base) sebagai lapis pengikat dan yaitu (HRS - WC) yang berada pada lapis permukaan yang paling atas, yang bersentuhan langsung dengan roda pada kendaraan.

Pada umumnya filler yang digunakan pada HRS adalah Semen Porland, fly ash batu bara ,dan kapur padam. Arang Tempurung Kelapa (Coconut Shell Charcoal) adalah residu yang mengandung karbon aktif yang dihasilkan dengan cara pemanasan pada suhu yang tinggi dengan bahan dasar tempurung kelapa. Dibandingkan dengan arang kayu dan arang sekam padi. Tujuan dalam penelitian ini untuk mengetahui kualitas dari modifikas campuran Hot Rolled Sheet - Wearing Course (HRSWC) dengan penambahan bahan serbuk arang tempurung kelapa.

\section{Tinjauan Pustaka}

Hot Roiled Sheet (HRS) adalah lapis tipis penutup yang terdiri atas campuran agregat bergradasi timpang, mineral pengisi aspal (filler) dan aspal dengan perbandingan tertentu pada perkerasan, yang nantinya dicampur serta dipadatkan dalam kondisi panas. Menurut Sukirman (1992:10) Menurut Spesifikasi Umum DPU Bina Marga Provinsi Jawa Timur (2018) HRS-Base mempunyai agregat kasar dengan proporsi fraksi lebih besar daripada HRS- WC. Sehingga hasil yang didapatkan memuaskan, pada HRS-WC maka untuk memenuhi semua ketentuan yang diberikan dalam spesifikasi perlu adanya pencampuran yang dirancang dengan baik. Dua kunci utama adalah: (1) Gradasi yang benar-benar senjang. Untuk memperoleh gradasi senjang, maka dilakukanlah pencampuran pasir halus dengan agregat pecah mesin; (2) Sisa rongga-rongga udara pada kepadatan membal (refusal density) harus memenuhi ketentuan yang ditunjukkan pada Spesifikasi ini. Apabila porsi agregat medium dengan ukuran butir maksimum $10 \mathrm{~mm}$ diperbesar maka akan diperoleh campuran HRS bergradasi semi senjang dengan menambah nilai stabilitas, yang selanjutnya disebut sebagai HRS-Base.

\section{Aspal Minyak}

Aspal merupakan material berwarna coklat tua atau hitam, pada suhu ruangan tertentu berbentuk padat hingga mendekati padat. Jika dipanaskan pada temperature tertentu, maka aspal tersebut dapat berubah bentuk menjadi lunak hingga cair. Sehingga dapat menyatukan agregat dalam pembuatan aspal beton atau dapat masuk kepori-pori agregat yang ada pada penyiraman pada pelaksanaan pelaburan atau macadam. Jika temperature mulai turun, kondisi aspal akan menjadi keras dan mengikat agregat yang berada pada tempatnya (sifat thermoplastic).

Tabel 1 Persyaratan Pengujian Aspal

\begin{tabular}{cccc}
\hline No & Jenis Pengujian & Metode Pengujian & Persyaratan \\
\hline 1 & Penetrasi, 25 ${ }^{\circ} \mathrm{C}, 100$ gram & SNI 06-2456-1991 & $60-70$ \\
\hline 2 & Titik Lembek & SNI 06-2456-1991 & $\geq 48$ \\
\hline 3 & Indeks Penetrasi & - & $\geq-1,0$ \\
\hline 4 & Daktilitas pada $25^{\circ} \mathrm{C}(\mathrm{cm})$ & SNI 06-2456-1991 & $\geq 100$ \\
\hline 5 & Titik Nyala & SNI 06-2456-1991 & $\geq 232$ \\
\hline 6 & Berat Jenis & SNI 06-2456-1991 & $\geq 1,0$ \\
\hline 7 & Berat Hilang & SNI 06-2456-1991 & $\leq 0,8$ \\
\hline
\end{tabular}




\section{Agregat}

Agregat adalah sekumpulan partikel - partikel batu pecah bulat, pasir atau agregat halus baik berupa agregat hasil alami maupun hasil pengolahan (penyaringan, pemecah). Pada bahan perkerasan lentur agregat merupakan komponen utamanya yaitu mengandung 90 - $95 \%$ agregat, sesuai persentase berat 75 - $85 \%$ agregat berdasarkan pada persentase volume [1]. Dengan demikian, daya dukung keawetan serta mutu perkerasan jalan dapat ditentukan dari sifat agregat serta hasil campuran agregat dengan pencampuran material lainnya. Secara umum bahan penyusun beton aspal terdiri dari agregat halus, agregat kasar, bahan pengisi (filler) serta aspal sebagai bahan pengikatnya. Dimana bahan - bahan tersebut sebelum digunakan telah melalui tahap pemeriksaan di laboratorium.

Tabel 2. Persyaratan Pengujian Agergat

\begin{tabular}{|c|c|c|c|c|}
\hline \multicolumn{3}{|c|}{ Pengujian } & Standar & Nilai \\
\hline Kekekalan Ben & Natri & Im Sulfat & \multirow{2}{*}{ SNI 3407:2008 } & Maks. $12 \%$ \\
\hline Agregat terhadap I & Larutan & ium Sulfat & & Maks. $18 \%$ \\
\hline \multirow{4}{*}{$\begin{array}{l}\text { Abrasi dengan mesin - } \\
\quad \text { los angeles } 1\end{array}$} & \multirow{2}{*}{$\begin{array}{c}\text { Campuran AC } \\
\text { modifikasi }\end{array}$} & 100 putaran & \multirow{4}{*}{ SNI 2417:2008 } & Maks.6\% \\
\hline & & 500 putaran & & Maks.30\%**) \\
\hline & \multirow{2}{*}{$\begin{array}{c}\text { Semua jenis campuran } \\
\text { aspal bergradasi } \\
\text { lainnya }\end{array}$} & 100 putaran & & Maks. $8 \%$ \\
\hline & & 500 putaran & & Maks. $30 \% * *)$ \\
\hline \multicolumn{3}{|c|}{ Kelekatan agregat terhadap aspal } & SNI 2439:2011 & Min.95\% \\
\hline \multicolumn{3}{|c|}{ Butir pecah terhadap aspal } & SNI 7619:2012 & $95 / 90 *)$ \\
\hline \multicolumn{3}{|c|}{ Partikel Pipih dan Lonjong } & $\begin{array}{c}\text { ASTM D4791 } \\
\text { Perbandingan 1:5 }\end{array}$ & Maks. $10 \%$ \\
\hline \multicolumn{3}{|c|}{ Material lolos Ayakan No 200} & SNI 03-4142-1996 & Maks.1\% \\
\hline
\end{tabular}

\section{Serbuk Arang Tempurung Kelapa}

Arang tempurung kelapa merupakan residu yang berwarna hitam yang mengandung karbon didalamnya. Arang tempurang Kelapa mengandung senyawa karbon non polar yang sama seperti senyawa karbon pada aspal. Serbuk arang tempurung kelapa ini dapat berupa butiran seperti pasir atau debu yang dihasilkan akibat penghancuran arang tempurung kelapa. Komposisi pada arang tempurung kelapa memiliki banyak sekali kandungan mineral.

\section{Uji Marshall}

Tabel 3. Ketentuan Sifat- Sifat Campuran Beraspal HRS

\begin{tabular}{|c|c|c|c|}
\hline \multicolumn{2}{|l|}{ Sifat-sifat Campuran } & \multicolumn{2}{|c|}{ Lataston } \\
\hline & & Lapis Aus & Lapis Fondasi \\
\hline Kadar Aspal efektif (\%) & Min & 5,9 & 5,5 \\
\hline Jumlah Tumbukan perbidang & & & \\
\hline \multirow[t]{2}{*}{ Rongga dalam campuran (\%) } & Min & & \\
\hline & Maks & & \\
\hline Rongga dalam Agregat (VMA) (\%) & Min & 18 & 17 \\
\hline Rongga terisi Aspal (\%) & Min & & \\
\hline Stabilitas Marshall (kg) & Min & & \\
\hline Marshall Quotient (kg/mm) & Min & & \\
\hline $\begin{array}{l}\text { Stabilitas Marshall sisa }(\%) \text { setelah } \\
\text { perendaman selama } 24 \text { jam }, 60^{\circ} \mathrm{C}\end{array}$ & Min & & \\
\hline
\end{tabular}


Pengujian marshall merupakan metode pengujian untuk mengukur stabilitas, flow dan $M Q$ (Marshall Quotient) dengan menggunakan spesifikasi HMA dengan gradasi lapisan untuk HRS dengan menggunakan Bina Marga 2018 revisi III divisi 6. Stabilitas merupakan nilai kemampuan campuran menerima beban hingga kondisi kelelehan plastis dinyatakan dalam kg, sedangkan flow merupakan kemampuan campuran aspal yang menerima beban hingga kondisi stabilitas dinyatakan dalam $\mathrm{mm}$, dan $M Q$ adalah hasil bagi antara nilai stabilitas dan flow yang berpengaruh pada tingkat fleksibilitas campuran aspal dinyatakan dalam $\mathrm{kg} / \mathrm{m}$.

\section{Metodologi}

Material agregat diambil dari AMP kemudian ditest di laboratorium untuk mengetahui sifat sifat fisiknya apakah sudah sesuai dengan sifat fisik yang disyaratkan pada spesifikasi. Material yang digunakan merupakan materialyang telah memenuhi persyaratan spesifikasi baik gradasi maupun sifat teknis lainnya. Material semen yang digunakan berasal dari perusahaan Swasta. Selanjutnya menentukan porsi campuran agregat agar dapat mengetahui gradasi campuran yang sesuai dengan spesifikasi. Kemudian membuat benda uji yang tidak memakai kandungan serbuk arang tempurung kelapa dengan variasi kadar aspal yaitu: $6,8 \%, 7,3 \%$, dan 7,8\%

Setelah melakukan pengujian Marshall, maka dilakukan analisa untuk mengetahui KAO. Setelah mengetahui KAO tersebut dibuatlah benda uji dengan kadar 0\%, 2\%, 4\%, 6\%, $8 \%$, dan 10\% dari KAO yang telah diketahui. Setelah membuat benda uji dengan variasi kadar Serbuk arang tempurung kelapa tersebut selanjutnya melakukan Marshall Test. Setelah pengujian Marshall dilakukan analisa dalam penetuan berapa prosentase kadar Serbuk Arang Tempurung Kelapa yang optimum.

\section{Hasil dan Pembahasan}

\section{Hasil Pemeriksaan Aspal Pen 60/70}

Hasil pemeriksaan Aspal Pen 60/70 dapat dilihat pada tabel 3.1 sebagai berikut

Tabel 4 Hasil Pengujian Aspal 60/70

\begin{tabular}{clccc}
\hline No & \multicolumn{1}{c}{ Jenis Pengujian } & Metode Pengujian & Persyaratan & $\begin{array}{c}\text { Hasil } \\
\text { Pemeriksaan }\end{array}$ \\
\hline 1 & Penetrasi, 25 ${ }^{\circ} \mathrm{C}, 100$ gram & SNI 06-2456-1991 & $60-70$ & 66.9 \\
\hline 2 & Titik Lembek & SNI 06-2456-1991 & $\geq 48$ & 58.5 \\
\hline 3 & Indeks Penetrasi & SNI 06-2456-1991 & $\geq 100$ & - \\
\hline 4 & Daktilitas pada 25 ${ }^{\circ} \mathrm{C}$ & SNI 06-2456-1991 & $\geq 200$ & 318 \\
\hline 5 & Titik Nyala & SNI 06-2456-1991 & $\geq 1.0$ & 1,06 \\
\hline 6 & Berat Jenis & SNI 06-2456-1991 & $\leq 0.8 \%$ & $0 \%$ \\
\hline 7 & Berat Kehilangan & &
\end{tabular}

Pada tabel diatas dapat dilihat pada pengujian aspal pen 60/70 telah memasuki spesifikasi yang sesuai dengan Spesifikasi Departement Umum Tahun 2018.

\section{Hasil Pemeriksaan Agregat}

Hasil pemeriksaan Agregat dapat dilihat pada tabel 3.2 sebagai berikut 
Tabel 5 Hasil Pengujian Agregat

\begin{tabular}{cccccc}
\hline No & Aggregate & $\begin{array}{c}\text { Bulk Spesific } \\
\text { Grafity }\end{array}$ & $\begin{array}{c}\text { Apparent Spesific } \\
\text { Gravity } \\
\text { (SSD) }\end{array}$ & $\begin{array}{c}\text { Apparent } \\
\text { Spesific } \\
\text { Gravity }\end{array}$ & Absorption \\
\hline \multirow{2}{*}{$\begin{array}{c}\text { Coarse } \\
\text { Aggregate }\end{array}$} & 2.583 & 2.625 & 2.695 & 1.607 \\
\hline 2 & $\begin{array}{c}\text { Medium } \\
\text { Aggregate }\end{array}$ & 2.561 & 2.602 & 2.671 & 1.599 \\
\hline 3 & $\begin{array}{c}\text { Fine } \\
\text { Aggregate }\end{array}$ & 2.572 & 2.609 & 2.670 & 1.420 \\
\hline
\end{tabular}
2018.

Pada tabel diatas pengujian Agregat diambil dari AMP telah sesuai Spesifikasi Umum Tahun

\section{Uji Marshall}

Kadar aspal pada pengujian ini yang dipakai pada kadar 7,3\% yang didapatklan dari hasil aspal optimum. Dengan kadar tersebut dibuatlah benda uji dengan menambahkan Serbuk arang tempurung kelapa dengan berbagai variasi, yaitu $0 \%, 2 \%, 4 \%, 6 \%, 8 \%$, dan $10 \%$. Masing - masing variasi dibuat sebanyak tiga benda uji. Berikut merupakan hasil analisis untuk menentukan kadar serbuk arang tempurung kelapa yang optimum. Berikut merupakan tabel hasil dari analisa pengujian Marshall dengan penambahan serbuk arang tempurung kelapa.

Tabel 6 Hasil pengujian Marshall dengan penambahan serbuk arang termpurung kelapa

\begin{tabular}{ccccccccc}
\hline \multirow{2}{*}{$\begin{array}{c}\text { MIX } \\
\text { PROPERTIS }\end{array}$} & \multirow{2}{*}{ UNIT } & \multicolumn{8}{c}{ RESULT TRIAL LAB } & \multicolumn{3}{c}{ SPEC } \\
\cline { 3 - 9 } & & $\mathbf{0 \%}$ & $\mathbf{2 \%}$ & $\mathbf{4 \%}$ & $\mathbf{6 \%}$ & $\mathbf{8 \%}$ & $\mathbf{1 0 \%}$ & \\
\hline VIM & $\mathbf{\%}$ & 4,18 & 4,27 & 4,34 & 4,69 & 4,86 & 4,98 & $\mathbf{4}-\mathbf{6}$ \\
\hline STABILITY & KG & 1052,72 & 1116,97 & 1191,10 & 1181,22 & 1131,79 & 1062,60 & Min 600 \\
\hline FLOW & MM & 3,40 & 3,27 & 3,18 & 3,07 & 3,03 & 2,90 & Min 3 \\
\hline MQ & KG/MM & 309,62 & 341,93 & 374,17 & 385,18 & 373,12 & 366,41 & Min 250 \\
\hline DENSITY & GR/CC & 2,259 & 2,257 & 2,255 & 2,247 & 2,243 & 2,240 & \\
\hline VMA & $\mathbf{\%}$ & 18,51 & 18,59 & 18,65 & 18,94 & 19,09 & 19,18 & Min 18 \\
\hline VFB & $\mathbf{\%}$ & 77,39 & 77,01 & 76,70 & 75,23 & 74,53 & 74,06 & Min 68 \\
\hline
\end{tabular}

\section{Nilai VMA}

Nilai VMA terus naik dengan bertambahnya kadar Serbuk Arang Tempurung Kelapa hal ini menunjukkan bahwa semakin tinggi kadar Serbuk Arang Tempurung Kelapa yang ditambahkan maka semakin tinggi nilai VMA yang didapatkan. Spesifikasi umum Bina Marga Tahun 2018 menetapkan bahwa nilai VMA untuk Hot Rolled Sheet - WC minimal 18\%. Sehingga seluruh kadar Serbuk Arang Tempurung Kelapa telah memenuhi Persyaratan. 


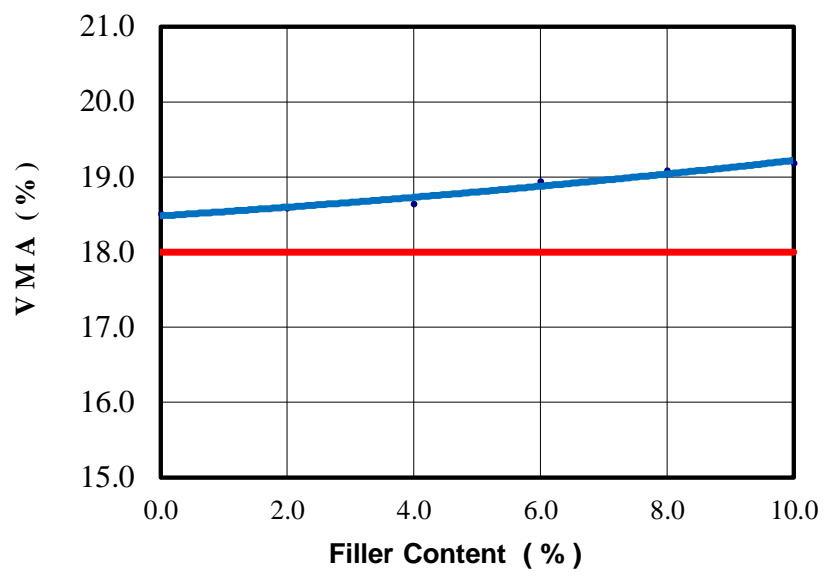

Gambar 1. Grafik VMA Modifikasi Penambahan Serbuk Arang tempurung Kelapa

\section{Nilai VIM}

Nilai VIM terus naik dengan bertambahnya kadar Serbuk Arang Tempurung Kelapa, hal ini menunjukkan bahwa kadar Serbuk Arang Tempurung Kelapa berpengaruh terhadap rongga dalam campuran atau nilai VIM. Semakin tinggi kadar Serbuk Arang Tempurung Kelapa yang ditambahkan maka volume rongga dalam campuran akan semakin Bertambah atau nilai VIM semakin Besar. Spesifikasi Bina Marga Tahun 2018 menetapkan bahwa rentang nilai VIM berkisar antara 4\% - 6\%. Sehingga seluruh kadar Serbuk Arang Tempurung Kelapa telah memenuhi Persyaratan.

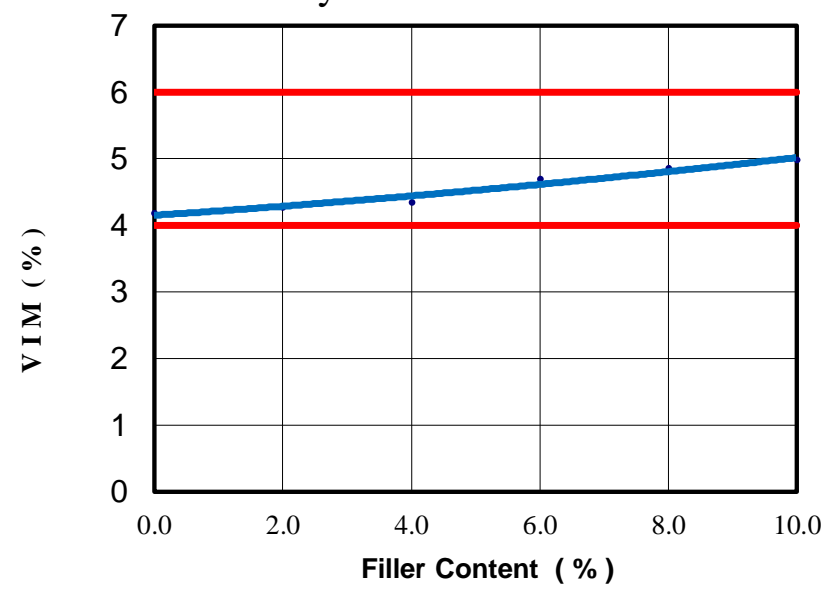

Gambar 2. Grafik VIM Modifikasi Penambahan Serbuk Arang tempurung Kelapa

\section{Nilai VFB}

Nilai VFB terus menurun dengan bertambahnya kadar Serbuk Arang Tempurung Kelapa dalam campuran. Hal ini disebabkan rongga dalam campuran membesar karena bertambahnya kadar Serbuk Arang Tempurung Kelapa yang menyelimuti butiran agregat. Spesifikasi Bina Marga Tahun 2018 menetapkan bahwa nilai VFB minimal $68 \%$. Nilai VFB pada kadar Serbuk Arang Tempurung Kelapa 0\%, 2\%, 4\%, 6\%, 8\%, dan 10\% telah memenuhi persyaratan tersebut. 


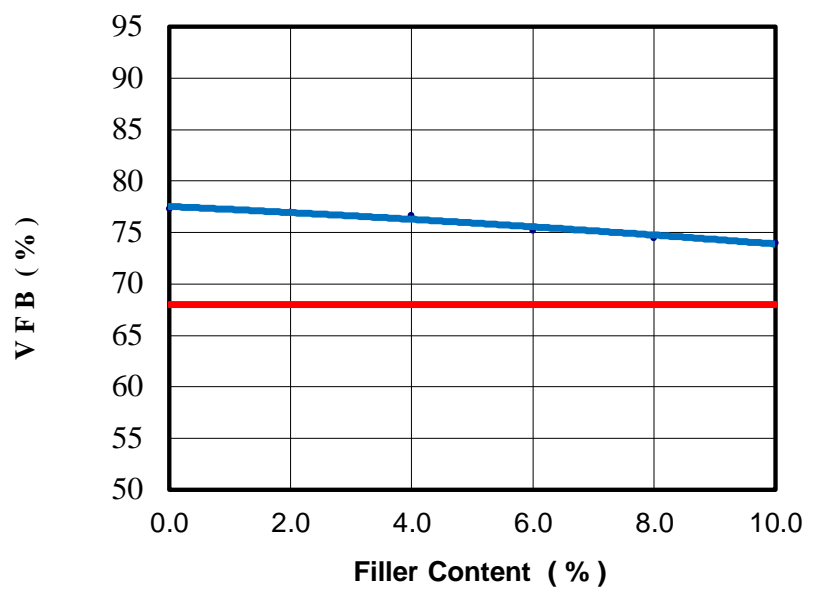

Gambar 3. Grafik VFB Modifikasi Penambahan Serbuk Arang tempurung Kelapa

\section{FLOW}

Nilai flow berbanding terbalik dengan kadar Serbuk Arang Tempurung Kelapa yang ditambahkan pada suatu campuran. Semakin tinggi kadar Serbuk Arang Tempurung Kelapa dalam campuran maka nilai flow akan semakin turun. Spesifikasi Bina Marga Tahun 2018 menetapka nilai flow untuk Hot Rolled Sheet - WC Minimum $3 \mathrm{~mm}$. Nilai flow untuk kadar Serbuk Arang Tempurung Kelapa 0\%, 2\%, 4\%, 6\%, 8\% telah memenuhi persyaratan tersebut dan untuk Penambahan 10\% tidak memenuhi Persyaratan Spesifikasi Umum Bina Marga 2018.

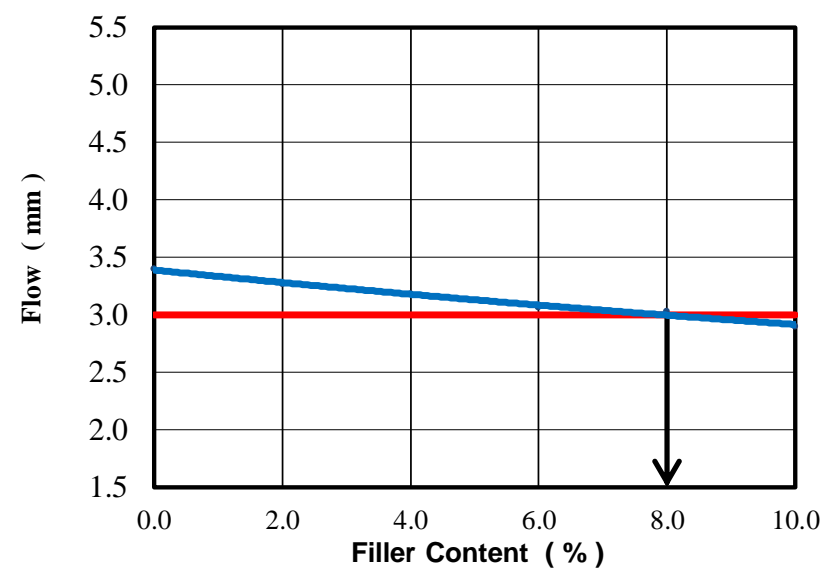

Gambar 4. Grafik Flow Modifikasi Penambahan Serbuk Arang tempurung Kelapa

\section{STABILITAS}

Berdasarkan Gambar 4.7 dapat dilihat bahwa pada kadar Serbuk Arang Tempurung Kelapa $2 \%$ didapatkan nilai stabilitas yaitu 1116,97 kg, dan pada kadar Serbuk Arang Tempurung Kelapa 4\% didapatkan nilai stabilitas terus meningkat yaitu $1191.1 \mathrm{~kg}$. Namun pada kadar aspal 6\% nilai stabilitas menurun. Hal ini menunjukkan bahwa nilai stabilitas akan meningkat jika kadar Serbuk Arang Tempurung Kelapa bertambah dan setelah mencapai batas optimum nilai stabilitas akan menurun. 


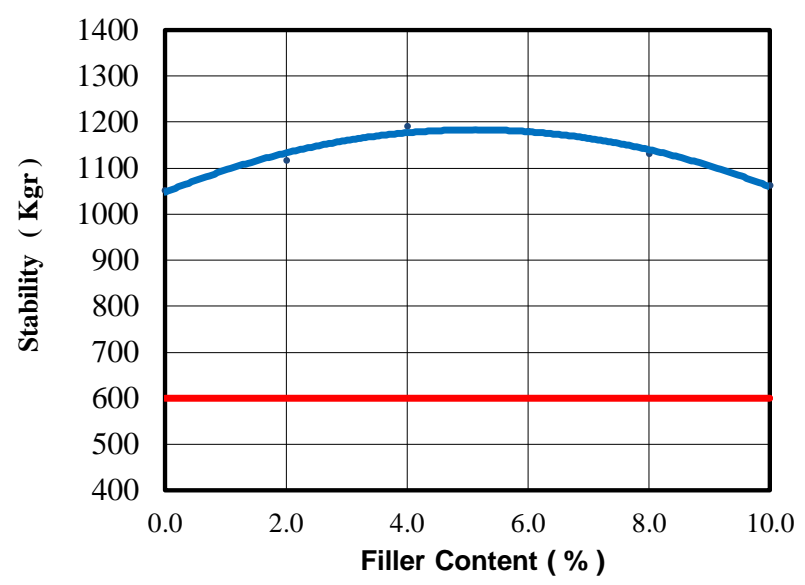

Gambar 5. Grafik Stabilitas Modifikasi Penambahan Serbuk Arang tempurung Kelapa

\section{MARSHALL QUOTIENT}

Nilai Marshall Quotient pada Gambar 4.15 naik pada kadar Serbuk Arang Tempurung Kelapa 2\% hingga pada kadar 6\% setelah itu pada kadar $8 \%$ mengalami penurunan. Hal ini disebabkan oleh nilai stabilitas akan menurun dengan penambahan kadar Serbuk Arang Tempurung Kelapa yang telah melampaui nilai optimum stabilitas, serta didukung dengan tingkat kelelehannya yang menurun dengan meningkatnya kadar aspal. Spesifikasi Bina Marga Tahun 2018 menetapkan batas minimum pada Marshall Qutient yaitu $250 \mathrm{~kg} / \mathrm{mm}$. Nilai Marshall quotient untuk kadar Serbuk Arang Tempurung Kelapa 0\%, 2\%, 4\%, 6\%, 8\%, dan $10 \%$ telah memenuhi persyaratan tersebut.

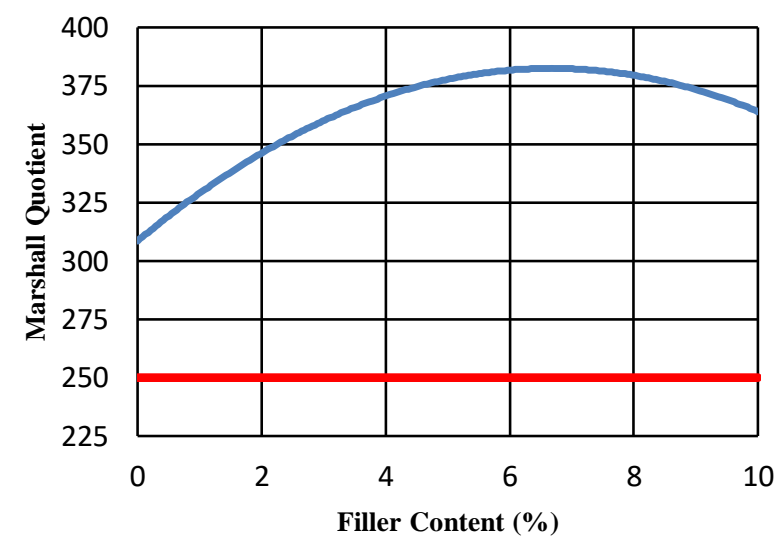

Gambar 6. Grafik Marshall quotient Modifikasi Penambahan Serbuk Arang tempurung Kelapa

\section{KADAR SERBUK ARANG TEMPURUNG KELAPA OPTIMUM}

Penentuan kadar Serbuk arang tempurung kelapa dilakukan dengan menggunakan analisa dari stabilitas, flow, Marshall Quotient (MQ), VIM, VMA, dan VFB dari data diatas. 


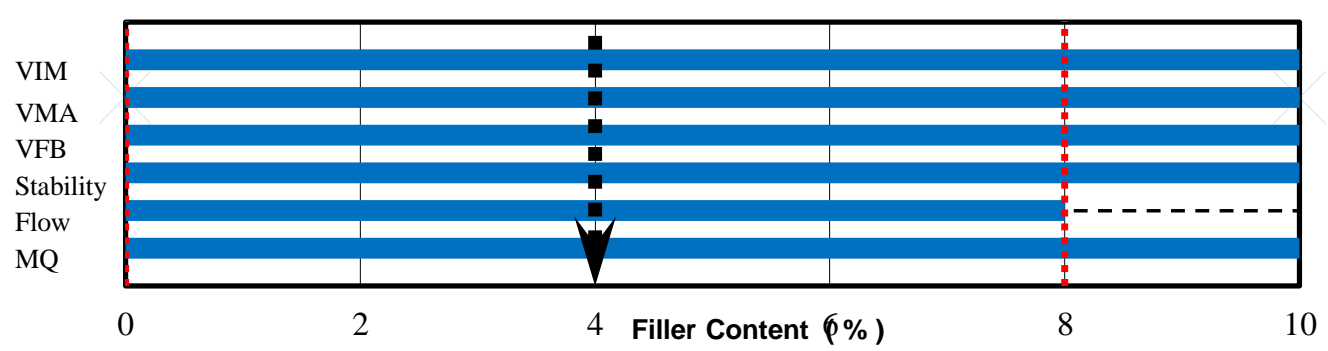

Gambar 7. Grafik Kesimpulan Modifikasi Penambahan Serbuk Arang tempurung Kelapa

Dari hasil yang didapatkan, untuk kadar penambahan Serbuk Arang Tempurung Kelapa yang baik serta optimum di kadar $4 \%$ dikarenakan pada kadar $4 \%$ nilai stabilitas nya merupakan yang tertinggi sehingga campuran aspal yang digunakan tetap stabil tanpa banyak terjadinya perubahan. Pada campuran 4\% juga sesuai dengan Spesifikasi Umum Bina Marga Tahun 2018, sedangkan untuk kadar $10 \%$ tidak memenuhi persyaratan.

\section{KESIMPULAN}

Dapat ditarik kesimpulan hasil yang paling optimum penambahan serbuk arang tempurung kelapa pada campuran HRS - WC sesuai dengan Spesifikasi Umum Bina Marga 2018 adalah pada kadar penambahan $4 \%$ serbuk arang tempurung kelapa. Dimana nilai pada penambahan $4 \%$ diperoleh nilai stabilitas $1191,1 \mathrm{Kg}$, nilai flow 3,18 mm, nilai MQ 373,12 kg/mm, nilai VIM 4,34\%, nilai VMA $18,65 \%$, nilai VFB 76,70\%.

\section{DAFTAR PUSTAKA}

[1] S. Sukirman, "Perencanaan Tebal Struktur Perkerasan Lentur," Bandung: Nova, 2010.

[2] B. Marga, "Spesifikasi Campuran Beraspal Panas pada Spesifikasi Umum Jalan dan Jembatan Edisi 2010," Direktorat Jendral Bina Marga, Jakarta, 2010.

[3] S. D. Y. Putri and K. H. Putra, "MODIFIKASI CAMPURAN PERKERASAN LASTON ACWC DENGAN PENAMBAHAN KADAR 8\% GILSONITE RESIN," in Prosiding Seminar Teknologi Perencanaan, Perancangan, Lingkungan dan Infrastruktur, 2019, vol. 1, no. 1, pp. 22-29.

[4] M. Mashuri, "Pengaruh Penggunaan Serbuk Arang Tempurung Kelapa Dan Variasi Jumlah Tumbukan Terhadap Karakteristik Campuran Beton Aspal," MEKTEK, vol. 10, no. 1.

[5] G. N. I. P. Pratama and A. M. Yusuf, "UJI TITIK NYALA DAN TITIK BAKAR SEMARBUT ASPAL TIPE 4 BERDASARKAN SNI 2433: 2011," INformasi dan Ekspose hasil Riset Teknik SIpil dan Arsitektur, vol. 15, no. 1, pp. 62-73, 2019. 
112 Jurnal Teknologi dan Manajemen, Vol 1, No 2, Juli 2020: 103-112

- Halaman ini sengaja dikosongkan - 